\title{
Reinforcing properties of novel and familiar solutions of saccharin for rats
}

\author{
MICHAEL DOMJAN, DOUGLAS GILLAN, and JEAN MARIE TRENT \\ University of Texas at Austin, Mezes 330, Austin, Texas 78712
}

\begin{abstract}
To evaluate the influence of flavor neophobia on the reinforcing properties of edibles, the leverpress behavior of rats was reinforced with either a novel or a familiar $2.0 \%$ solution of sodium saccharin following preliminary training with water reinforcement. The familiar saccharin flavor was much more effective in reinforcing instrumental behavior than was the novel saccharin. In fact, reinforcement with a novel saccharin flavor initially did not stimulate more responding than what was observed in another group of subjects given no reward. Repeated training with the novel saccharin reward gradually increased the rate of leverpressing, consistent with a counterconditioning interpretation. However, this counterconditioning did not produce the increased resistance to extinction in the final phase of the experiment which is predicted by the general theory of persistence (Amsel, 1972).
\end{abstract}

Incentives such as food and water motivate both consummatory and instrumental behaviors. The consummatory response to an incentive is regulated by a variety of factors including the novelty of the incentive object. Food novelty has been observed to suppress ingestion in a wide variety of animals including rats (Barnett, 1956), birds (Rabinowitch, 1968, 1969), and humans (Hollinger \& Roberts, 1929). Studies of this flavor neophobia phenomenon have been restricted to observations of the effects of novelty on consummatory behavior. However, flavor neophobia may also influence the instrumental reinforcing properties of incentive objects. If this were the case, it would indicate that food neophobia plays a more important role in the organization of behavior than heretofore demonstrated.

Consummatory and instrumental responses to incentive stimuli are not always highly correlated (e.g., Holman, 1975; Miller, Bailey, \& Stevenson, 1950). Therefore, a comparison of instrumental performance rewarded by novel and familiar substances is necessary to determine the influence of food neophobia on the reinforcing properties of edible incentives. To this end, the present study was designed to evaluate the effectiveness of a novel and a familiar saccharin solution in reinforcing leverpress responding in rats. It was expected that the novel saccharin solution would be less rewarding than the familiar saccharin. To discover whether the novel saccharin flavor had any reinforcing consequences, subjects rewarded with the novel saccharin solution

The research was supported by funds from a Biomedical Sciences Support Grant to the University of Texas as well as N.I.M.H. Grant No. MH 25007-01A1 to M. Domjan. We wish to thank S. Holliday and R. Fabes for their technical assistance. Requests for reprints should be addressed to $M$. Domjan, Department of Psychology, University of Texas at Austin, Austin, Texas 78712 . were compared to an extinction group tested without reinforcement.

An additional purpose of the experiment was to determine whether, given sufficient training, subjects reinforced with a novel saccharin solution would come to respond as often as others reinforced with the familiar saccharin. The extinction performance of these two groups was then compared to see if the general theory of persistence (Amsel, 1972) is applicable to this situation.

\section{METHOD}

Twenty-five male Sprague-Dawley rats, $200-250 \mathrm{~g}$ at the beginning of the experiment, were individually housed in a vivarium, illuminated 800 to $2000 \mathrm{~h}$ daily. Subjects initially had continual access to water and Purina Rat Chow, but 5 days after arrival in the laboratory, access to water was limited to $30 \mathrm{~min}$ daily for 6 days. For the next 25 days, subjects received access to fluids for $60 \mathrm{~min}$ each day. During the first $30 \mathrm{~min}$ of this period, the eight subjects assigned to Group Familiar and four of the nine subjects assigned to Group Extinction received access to a $2.0 \%$ solution of sodium saccharin (weight/volume in tap water); Group Novel $(n=8)$ and the remaining five subjects of Group Extinction received access to tap water. During the second $30 \mathrm{~min}$ of the fluid access period, all subjects received access to water. The fluids were presented in inverted graduated drinking tubes with metal spouts which permitted measurements of intake accurate to $.25 \mathrm{ml}$.

Following the saccharin-familiarization phase, all subjects were shaped to press a lever for $.05 \mathrm{ml}$ water reinforcement and then trained on a continuous reinforcement schedule in a standard instrumental conditioning chamber (Lafayette Model 8000) positioned in a sound-attenuating enclosure. Experimental sessions, scheduled on alternate days, lasted $15 \mathrm{~min}$. Subjects received 30-min daily access to water which on training days occurred after the leverpress session. Any subject that made less than 50 responses during the second session received one to three remedial sessions. Upon meeting the 50-response criterion, all subjects received a third regular water-reinforcement session. During Sessions 4-6, each leverpress response was reinforced with $.05 \mathrm{ml}$ of the $2.0 \%$ saccharin solution for Groups Familiar and Novel, while reinforcement was discontinued for Group Extinction. Groups Familiar and Novel then received seven additional 
saccharin-reinforcement sessions followed by extinction during Sessions 14-16. Data were recorded for the total number of responses performed during each session as well as the number of leverpresses made during successive 30 -sec intervals of Session 4 (the first time saccharin was introduced as the reinforcer for Groups Familiar and Novel) and Session 14 (the first time Groups Familiar and Novel experienced extinction). Statistical comparisons were made with the Mann-Whitney U test (two-tailed) at the .05 level of significance.

\section{RESULTS}

\section{Saccharin Familiarization}

Since the patterns of intake evident during the initial phase of the experiment were very similar to what we previously reported with this procedure (Domjan, 1976; Domjan \& Gillan, Note 1), these data will be only briefly described. During the first $30 \mathrm{~min}$ of fluid availability each day, subjects which had access to water drank a mean of 16.0 to $21.5 \mathrm{ml}$, with no systematic trend in the daily variations. In contrast, subjects given access to the $2.0 \%$ saccharin solution during the first $30 \mathrm{~min}$ each day initially drank only a mean of $2.5 \mathrm{ml}$. With repeated exposure to the solution, saccharin intakes gradually increased. By the 15th exposure, these subjects drank as much saccharin as the others drank of water during comparable periods. Thus, the initial neophobia or reluctance to drink the saccharin solution became attenuated as subjects became more familiar with the saccharin flavor.

\section{Leverpress Training}

The number of leverpress responses each group performed during the successive 15-min sessions is displayed in Figure $1 .^{1}$ No reliable group differences in responding for water reinforcement were observed. During the last water-reinforcement session (Session

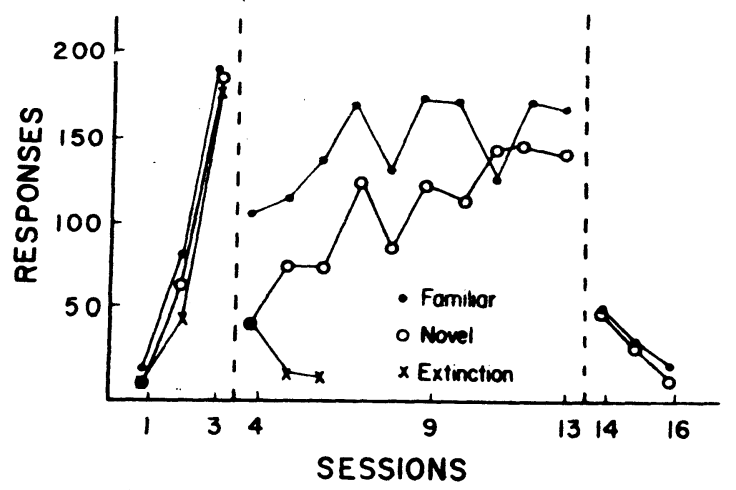

Figure 1. Mean number of leverpress responses performed during successive 15 -min sessions. All groups were reinforced with water on a continuous reinforcement schedule during Sessions 1-3. Starting in Session 4, a $2.0 \%$ solution of saccharin was introduced as the reward for Groups Novel and Familiar, while Group Extinction received no reinforcement. Reinforcement was also discontinued for Groups Novel and Familiar during Sessions 14-16.

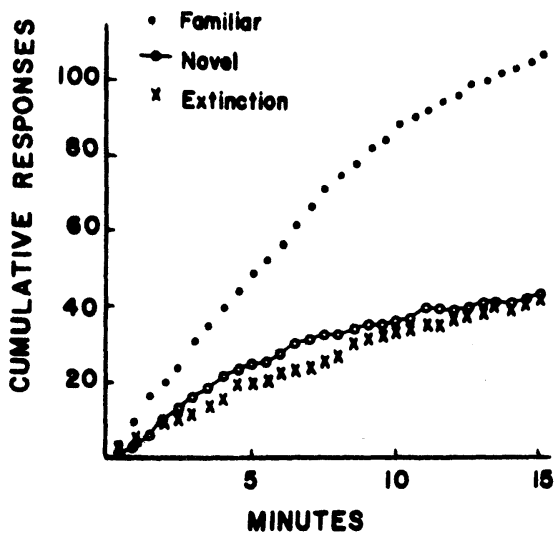

Figure 2. Mean cumulative number of leverpress responses performed during successive 30-sec periods of Session 4, the first time saccharin was introduced as the reinforcer for Groups Novel and Familiar and reinforcement was discontinued for Group Extinction.

3), the various groups performed from 178 to 190 responses.

During Session 4, in which saccharin was introduced as the reinforcer for Groups Familiar and Novel and responses were no longer reinforced for Group Extinction, each subject made fewer responses than during the preceding session with water reward. However, Group Familiar, which had extensive prior exposure to the saccharin reward, performed considerably more leverpress responses than either Group Novel or Group Extinction (Mann-Whitney Us $=4.5$ and 2.0 , respectively, ps $<.01$ two-tailed). This finding indicates that the saccharin solution was much more effective in reinforcing leverpressing when it was familiar than when it was novel and that the familiar saccharin flavor could maintain responding above extinction levels.

In contrast to the rewarding value of the familiar saccharin solution, the novel saccharin reward did not stimulate more responding than that observed with no reinforcement. Groups Novel and Extinction performed a comparable number of responses during Session 4. Because the total number of responses observed at the end of a session may obscure possible group differences which exist earlier in the session, the number of responses performed during Session 4 was also recorded at 30-sec intervals. These data, presented in Figure 2, provide further evidence that the novel saccharin solution was no more effective in reinforcing leverpress responses than was the absence of reinforcement. Groups Novel and Extinction displayed similar rates of leverpressing throughout Session 4.

The comparable performance of Groups Novel and Extinction during Session 4 would be a trivial finding if subjects in Group Novel totally ignored and did not drink the saccharin reward. However, this did not appear to be the case. Subjects in Group Novel were 


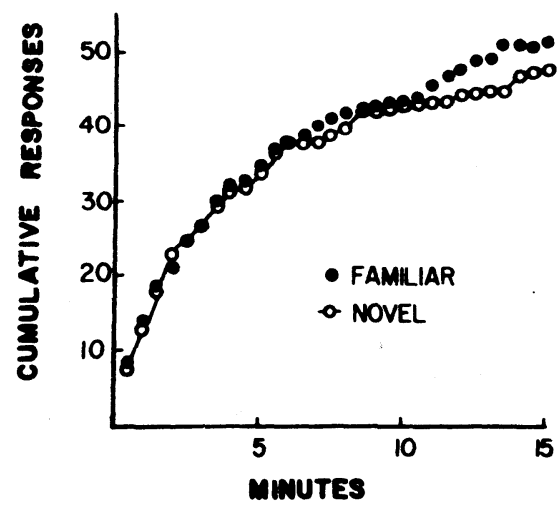

Figure 3. Mean cumulative number of leverpress responses performed during successive 30-sec periods of Session 14, the first time reinforcement was discontinued for Groups Novel and Familiar.

observed to not drink a mean of only 9.2 of the 44 saccharin rewards they received. To further confirm that subjects will drink some of a novel $2.0 \%$ saccharin solution during their first $15 \mathrm{~min}$ of access to it, five additional naive water deprived rats were given the saccharin solution to drink in the home cage for $15 \mathrm{~min}$ and were observed to drink a mean of $2.3 \mathrm{ml}$. Therefore, the comparable performance of Groups Novel and Extinction during Session 4 cannot be attributed to total avoidance of the novel saccharin solution on the part of Group Novel subjects.

Repeated training with the saccharin reinforcement gradually increase the response rate of both Groups Novel and Familiar. However, this increase was greater for Group Novel so that by the 10th saccharin-reinforcement session (Session 13), Groups Novel and Familiar performed a comparable number of responses. During the subsequent extinction Sessions 14-16, responding was observed to decline, with no reliable differences between Groups Novel and Familiar detected in either the total number of responses per session or the number of leverpresses made during successive 30-sec intervals of Sessions 14 (see Figures 1 and 3).

\section{DISCUSSION}

The present results indicate that the novelty of a flavored fluid not only suppresses ingestive activities but also reduces the effectiveness of the substance as a reward for instrumental performance. This finding confirms previous reports that, in certain circumstances, familiar edibles are more reinforcing than novel solutions (Smith \& Capretta, 1956; Wetzel, 1959) and indicates that flavor neophobia is important for both food selection as well as instrumental reinforcement.

The novel saccharin solution was not only less effective as a reward than the familiar saccharin but also failed to maintain leverpress responding above levels which occurred in the absence of reinforcement. In terms of their instrumental performance, subjects receiving the novel saccharin reward initially behaved as if they received no reinforcement, despite the fact that they did not totally ignore the novel saccharin solution and drank it most of the times it was delivered. This result indicates that flavor neophobia has a greater impact on the instrumental reinforcing properties of an edible than on consummatory behavior.

As subjects received more experience with the novel saccharin solution, they responded more often for it, until eventually Groups Novel and Familiar displayed comparable rates of leverpressing. This finding demonstrates that food neophobia can become attenuated during the course of instrumental training.

The fact that the increase in response rate from the first to the last saccharin-reinforcement session was greater for Group Novel than Group Familiar suggests that the leverpress response became counterconditioned to a greater extent in Group Novel. Therefore, the general theory of persistence (Amsel, 1972) predicts that Group Novel would be more resistant to extinction than Group Familiar. The present failure to obtain such a finding indicates a limitation of the theory (see also Wong, Scull, \& Amsel, 1970).

\section{REFERENCE NOTE}

1. Domjan, M., and Gillan, D. Role of novelty in the aversion for increasingly concentrated taste solutions. In preparation.

\section{REFERENCES}

AMSEL, A. Behavioral habituation, counter-conditioning, and a general theory of persistence. In A. H. Black and W. F. Prokasy (Eds.), Classical conditioning II: Current research and theory. New York: Appleton-Century-Crofts, 1972.

BARNETt, S. A. Behaviour components in the feeding of wild and laboratory rats. Behaviour, 1956, 9, 24-43.

Domsan, M. Determinants of the enhancement of flavored-water intake by prior exposure. Journal of Experimental Psychology: Animal Behavior Processes, in press, 1976.

Hollinger, M., \& Roberts, L. J. Overcoming food dislikes: A study with evaporated milk. Journal of Home Economics, 1929, 21, 923-932.

Holman, E. W. Some conditions for the dissociation of consummatory and instrumental behavior. Learning and Motivation, 1975, 6, 358-366.

Miller, N. E. Bailey, C. J., \& Stevenson, J. A. P. Decreased "hunger" but increased food intake resulting from hypothalamic lesions. Science, 1950, 112, 156-159.

RABINOWITCH, V. The role of experience in the development of food preferences in gull chicks. Animal Behaviour, 1968, 16, $425-428$.

Rabinowitch, V. The role of experience in the development and retention of seed preferences in zebra finches. Behavior, $1969,33,222-236$.

Smith, M. P., \& Capretta, P. J. Effects of drive level and experience on the reward value of saccharin solutions. Journal of Comparative and Physiological Psychology, 1956, 49, 553-557.

WETZEL, R. J. The effect of experience with a taste reward. Journal of Comparative and Physiological Psychology, 1959, 52, 267-271.

Wong, P. T., Scull, J., \& Amsel, A. The effect of partial "quinine" reward on acquisition and extinction. Psychonomic Science, 1970, 18, 48-49.

\section{NOTE}

1. The data for all of the subjects in Group Extinction were pooled since those which had been familiarized with saccharin performed comparably to those which had not received this treatment.

(Received for publication October 17, 1975.) 